\title{
Enfermedad de Wilson
}

\author{
Dr. Rafael Prudencio B. ${ }^{1}$; Dr. Femando Betancourt M. ${ }^{1}$ \\ Dr. Francisco Larrain B. ${ }^{2}$; Dr. Osvaldo Danus V.2

\section{Wilson's Disease}

\begin{abstract}
A case of pure hepatic form of Wilson's disease is reported in an elght years old girl. The diagnosis was supported by indirect methods such as parent's ceruloplasmin plasmatic levels and a therapeutic trial, which was followed by typical changes in arine cooper output. It is suggested that a Wilson's disease diagnosis should be considered in all cases of chronic hepatic disease in childhood in order to avoid newrologic injury.
\end{abstract}

La degeneración Hepatolenticular o Enfermedad de Wilson es una enfermedad poco frecuente, pero importante de tener presente, pues el buen éxito depende en gran medida de un diagnóstico precoz. En pediatría esta eventualidad debe considerarse en todo caso de enfermedad hepática cuyas manifestaciones clínicas o curso evolutivo salgan del esquema esperado.

La Enfermedad de Wilson es una entidad nosológica de origen congénito determinada por una alteración metabólica del hepatocito que condiciona una disminución significativa y permanente de la ceruplasmina, una alfa-2-globulina, que actúa como principal transportadora del cobre. Debido a este déficit se produce un acúmulo progresivo de cobre en el hígado, córnea, túbulo renal, cerebro y otras que determinan las modalidades clínicas de la enfermedad ${ }^{1 \cdot 2}$.

El diagnóstico se sospecha por algunos de los síndromes clínicos unidos a un descenso de ceru. loplasmina en el plasma, pero la certificación se obtiene al encontrar un aumento del contenido del cobre en el hígado superior a $100 \mathrm{mg} / \mathrm{g}$ de tejido seco, técnica elaborada y de difícil realización en nuestro medio. Por lo tanto en la práctica, el diagnóstico descansa en factores indirectos ya que la sola determinación de ceruloplasmina es un elemento insuficiente, dada sus variaciones en otras situaciones como desnutrición, malabsorción intestinal, enteropatia exudatoria, sindrome nefrótico, daño hepático crónico de otro origen, etc... ${ }^{3}$.

En esta oportunidad se da a conocer un nuevo caso clínico de esta entidad y se muestra el camino seguido para precisar el diagnóstico, que constituye un método adecuado, práctico y de alto rendimiento para nuestro medio.

1 Departamento de Pediatria del Hospital Dr. Roberto del Rio.

2 Lnidad de Gastroenterologia del Hospital Dr. Roberto del Río.

\section{Caso Clínico}

O.G.A. Sexo femenino, Edad: 8 años. Consultó a la edad de 7 años 11 meses. Había comenzado dos meses antes con astenia, anorexia, coluria e ictericia por lo cual fue al consultorio diagnosticándose "Hepatitis Aguda". Dejada en reposo se observó disminución de la ictericia en un período aproximado de 15 días, pero sus transaminasas seguían elevadas, tres veces más que lo normal, a los dos meses de evolución, aunque no tenía síntomas.

En esa época el examen físico era normal, Bilirubinemia Directa $0,35 \mathrm{mg} \%$. Total $1.00 \mathrm{mg} \%$, Transaminasa pirúvica $55 \mathrm{U} / \mathrm{ml}$.

A los 8 años y un mes tenia, desde 2 semanas antes, compromiso del estado general, alzas febriles intermitentes hasta $39^{\circ} \mathrm{C}$, aumento de volumen abdominal, edema facial especialmente palpebral, más acentuado en las mañanas, agregándose en los últimos 4 días edema de miembros inferiores y disminución de la diuresis.

Fue admitida al Hospital, ingresando afebril, con $27,2 \mathrm{~kg}$ de peso, lúcida, con leve palidez de piel y mucosas; edema leve de los párpados, moderado en extremidades inferiores y región lumbosacra; abdomen globuloso, circulación colateral incipiente, matiđez hídrica desplazable, signo de la ola positjvo; hígado palpable $1 \mathrm{~cm}$ bajo el reborde costal derecho, blando de borde regular; bazo no palpable. Hemograma: reticulocitos $6,8 \%$ (hemograma de $21 / 2$ meses antes normal); plaquetas y serie blanca: normales. Protrombinemia $32 \%$ que sigue baja luego de tratar con vitamina $\mathrm{K}$ con persistencia de hipoprotrombinemias de hasta $23 \%$. Proteinemia $5,78 \mathrm{~g} \%$; electroforesis de protejnas: hipoalbuminemia, hipergamaglobulinemia de $2,73(\mathrm{~N}: 0,7$ a 1,5$)$, mayor de $20 \%$. Sedimento Urinario: proteinuria 36 $\mathrm{mg} \%$, hematíes $80 \times \mathrm{mm}^{3}$ leucocitos $60 \times \mathrm{mm}^{3}$, urobilina positiva; Proteinuria de 24 horas: 285 $\mathrm{mg} / 24 \mathrm{hrs}$, densidad 1006, pH alcalino. Osmolaridad urinaria $660 \mathrm{mOs} / \mathrm{I}$. Creatinemia $0,54 \mathrm{mg} \%$, Nitrógeno Ureico $9,5 \mathrm{mg} \%$. Relación $\mathrm{O} / \mathrm{P}$ de elec- 
trolitos normal. Células de Lupus negativo; Anticuerpos antinucleares, negativo.

Espontáneamente los exámenes urinarios se normalizaron, manteniéndose siempre ura buena función urinaria durante toda la evolución.

La biopsia hepática no se pudo realizar por hipoprotrombinemia persistente sin respuesta a la administración de vitamina $\mathrm{K}$ y plasma.

La concentración de ceruloplasmina en el plasma fue de $4,3 \mathrm{mg} \%$ (n/20 a $40 \%$ ), por este motivo se investigó también a los padres (madre 20,8 $\mathrm{mg} \%$ : padre 12,7 mg\%). El examen of talmológico reveló la existencia de anillo de Kayser Fleischer.

Por las manifestaciones clinicas $y$ las cifras muy bajas de ceruloplasmina se hizo el diagnóstico de enfermedad de Wilson, que además se apoyó en la existencia del anillo de Kayser Fleischer y un esquema familiar compatible (padre: "portador asintomático") y se indicó tratamiento de prueba con D-Penicilamina con la finalidad de comprobar en la orina una curva de depleción de cobre, iniciándolo con $20 \mathrm{mg} / \mathrm{kilo} / \mathrm{d} \mathrm{a}_{\text {, }}$ previa dosificación de cobre en orina basal de 24 horas.

Las dosificaciones seriadas de cobre en orina de 24 horas en el $1^{\circ}, 2^{\circ} 4^{\circ}$ y $8^{\circ}$ días de tratamiento dieron los siguientes valores (Tabla 1 ).

Tabla 1.

Concentración urinaria de cobre antes y después de la administración de D-Penicilamina.

Basal: (48 horas antes del tratamiento: $0,54 \mathrm{mg} /$ ) Post tratamiento:

ler día

$2^{0}$ día

$4^{\circ}$ día

80 día

$2,04 \mathrm{mg} / 1$
$1,21 \mathrm{mg} / 1$
$1,50 \mathrm{mg} / 1$
$2,0 \mathrm{mg} / 1$

La evaluación neurológica fue normal.

Se dio de alta con indicación de mantener re. poso relatjvo y régimen hiperprotéico, hiposódico y tratamiento con D-Penicilamina 500 $\mathrm{mg} / \mathrm{dia}$, Furosemida dos veces a la semana y Gluconato de potasio $3 \mathrm{~g} /$ día.

En un control efectuado $21 / 2$ meses después estaba en buenas condiciones, activa, asintomática, sin signos de ascitis, hígado duro a nivel del reborde costal en el epigastrio; electrolitos plasmáticos normales. A los 5 meses de trata. miento se mantiene asintomática con albuminemia normal $(3,5 \mathrm{~g} / 1)$ Alfa 2 globulina descendida $(0,45 \mathrm{~g} / 1)$ y gamaglobulinemia normal $(0,96 \mathrm{~g} / 1)$, ceruloplasmina $4,3 \mathrm{mg} \%$ y protrombinemia $66 \%$.

\section{COMENTARIO}

Es difícil precisar si el primer episodio que presentó esta paciente, catalogado como hepatitis aguda, correspondió realmente a esa patología o bien sólo fue un episodio de la Enfermedad de Wilson. En efecto, en esa oportunidad no se realizó estudio de marcadores virales para la hepatitis o estudio hepático que pudieran haber dado un fundamento más valedero a aquel diagnóstico.

En nuestra experiencia es corriente que los niños portadores de Enfermedad de Wilson presenten entre sus antecedentes, cuadros clínicos compatibles con Hepatitis Aguda ${ }^{4}$.

En este caso el diagnóstico de Enfermedad de Wilson parece suficientemente fundamentado. En realidad, la sospecha clínica se tuvo al analizar el cuadro clínico de ingreso caracterizado por un síndrome propio de daño crónico del hígado.

En nuestro medio, la hepatitis viral es una enfermedad con alta incidencia, pero de acuerdo con los estudios epidemiológicos efectuados ${ }^{5}$ es condicionada en alta proporción por Virus A. de tal modo que la hepatitis crónica es una excepción en la edad escolar. La cifra baja de ceruloplasmina constituye un elemento de gran valor para orientar la investigación clinica hacia la Enfermedad de Wilson. Aunque ha sido señalado que el daño crónico hepático de otras etiologias puede presentar cifras descendidas de ceruloplasmina ${ }^{3}$ esta situación no se ha dado en nuestra experiencia ${ }^{6}$ además que las cifras presentadas por el caso en discusión fueron extremadamente bajas.

El depósito de cobre en la cómea es un elemento de gran ayuda diagnóstica, pero no siempre está presente, por este motivo la investigación del grupo familiar buscando portadores asintomáticos de niveles bajos de ceruloplasmina es muy importante. Esta situación siempre ha estado presente en nuestra casuística observándose valores entre 10 y $17 \mathrm{mg} \%$ en uno de los padres o hermanos.

Ante la sospecha clínica, la prueba terapéutica analizando la excreción urinaria de cobre en la forma señalada es fundamental y por último, la evolución experimentada en el largo plazo, que demostró regresión total de los sintomas y normaljzación de los parámetros de función hepática, como la electroforesis de proteínas y protrombinemia, corroboraron el diagnóstico, tanto más cuando en concomitancia con este hecho persistió sin variación el descenso de alfa -2 globulina y ceruloplasmina plasmática como era de esperar.

El caso presentado ser̃ala la importancia del diagnóstico precoz de esta enfermedad ya que en esta paciente se obtuvo una recuperación total en un corto periodo $y$ fue posible evitar el daño neurológico que habitualmente es grave y de difícil manejo clínico. 


\section{RESUMEN}

Se analiza un caso de Enfermedad de Wilson de forma hepática pura en una niña de 8 años de edad. E1 djagnóstico fue apoyado en métodos indirectos como niveles de ceruloplasmina en los padres y prueba terapéutica con una curya típica de eliminación urinaria de cobre.

El diagnóstico de Enfermedad de Wilson deberá tenerse presente en todos aquellos niños que presenten una enfermedad hepática crónica o de evolución tórpida cuya etiología no aparezca clara, de tal manera de evitar el compromiso neuro. lógico que habitualmente es más tardio.

\section{REFERENCIAS}

1 Sitvermen, A. et al. Pediatric Clinical Gastroenterology. $2^{\circ}$ ed Saint Louis, The C.V. Mosby Co. 1971, pp.407.

2 Walsh, J.M. Wilson's Disease. The presenting syntoms. Arch Dis Child 37: 253, 1962.

3 Walsh, $J, M$, and I. Brigess. Ceruloplasmin in liver disease. A diagnostic pit fall. Lancet $2: 263,1962$.

4 Danis, $O$. y cols. Enfemedad de Wilson. Pediatria (Stgo.) 18: 99, 1975.

5 Zacarias, J, y cols. Estudios de anticuerpos de Hepatitis A en niños. Bol. Med. Hosp. Inf. México 36: 571 , 1979.

6arraín, F y cols. Niveles plasmáticos de Ceruloplasmina y Cobre en el daño hepático crónico del niño. Rev. Chil. Pediatr. 46: 351, 1975. 